Article

\title{
Performance and Stability of Tenofovir Alafenamide Formulations within Subcutaneous Biodegradable Implants for HIV Pre-Exposure Prophylaxis (PrEP)
}

\author{
Linying Li ${ }^{1}{ }^{1}$, Leah M. Johnson ${ }^{1}$, , Sai Archana Krovi ${ }^{1}$, Zach R. Demkovich ${ }^{2}$ and \\ Ariane van der Straten ${ }^{2}$ (D) \\ 1 Engineered Systems, RTI International, 3040 E Cornwallis Road, Research Triangle Park, \\ Durham, NC 27709, USA; ali@rti.org (L.L.); akrovi@rti.org (S.A.K.) \\ 2 Women's Global Health Imperative, RTI International, 2150 Shattuck avenue, Berkeley, CA 94704, USA; \\ zdemkovich@rti.org (Z.R.D.); ariane@rti.org (A.v.d.S.) \\ * Correspondence: leahjohnson@rti.org; Tel.: +1-919-541-7233
}

Received: 8 October 2020; Accepted: 30 October 2020; Published: 5 November 2020

\begin{abstract}
A critical need exists to develop diverse biomedical strategies for the widespread use of HIV Pre-Exposure Prophylaxis (HIV PrEP). This manuscript describes a subcutaneous reservoir-style implant for long-acting delivery of tenofovir alafenamide (TAF) for HIV PrEP. We detail key parameters of the TAF formulation that affect implant performance, including TAF ionization form, the selection of excipient and the exposure to aqueous conditions. Both in-vitro studies and shelf stability tests demonstrate enhanced performance for TAF freebase $\left(\mathrm{TAF}_{\mathrm{FB}}\right)$ in this long-acting implant platform, as $\mathrm{TAF}_{\mathrm{FB}}$ maintains higher chemical stability than the TAF hemifumarate salt $\left(\mathrm{TAF}_{\mathrm{HF}}\right)$. We also examined the hydrolytic degradation profiles of various formulations of TAF and identified inflection points for the onset of the accelerated drug hydrolysis within the implant using a two-line model. The compositions of unstable formulations are characterized by liquid chromatography-mass spectrometry (LC-MS) and are correlated to predominant products of the TAF hydrolytic pathways. The hydrolysis rate of TAF is affected by $\mathrm{pH}$ and water content in the implant microenvironment. We further demonstrate the ability to substantially delay the degradation of TAF by reducing the rates of drug release and thus lowering the water ingress rate. Using this approach, we achieved sustained release of $\mathrm{TAF}_{\mathrm{FB}}$ formulations over 240 days and maintained $>93 \%$ TAF purity under simulated physiological conditions. The opportunities for optimization of TAF formulations in this biodegradable implant supports further advancement of strategies to address long-acting HIV PrEP.
\end{abstract}

Keywords: HIV pre-exposure prophylaxis; tenofovir alafenamide; implant; long-acting drug delivery; poly( $\varepsilon$-caprolactone) (PCL); biodegradable polymer

\section{Introduction}

There are an estimated 38 million people presently living with HIV globally [1]. Although the annual numbers of newly infected people has steadily declined, 1.7 million new infections were reported in 2019 [2]. Progress for further reduction of new infections is challenging, as some countries have experienced rising rates and more than $50 \%$ of key populations still do not have access to current HIV prevention services [1,2]. This suggests that coverage with the currently available HIV prevention product regimens, such as oral pre-exposure prophylaxis (PrEP) is insufficient. A broader range of HIV prevention products that extend beyond daily oral therapy—such as long-acting (LA) injectables, implants and topical methods-could further reduce the rate of new infections overall and in key 
populations. These prevention products are at different stages of the development pipeline. The furthest along under regulatory review is the monthly dapivirine ring [3]. The bi-monthly cabotegravir injectable (CAB-LA) is in phase III trials and was shown recently to be more effective than daily oral PrEP [4]. Earlier in the LA-PrEP product pipeline are implants, which are typically rod-shaped drug delivery systems made from biocompatible material. Implants are inserted underneath the skin and reside subcutaneously to release therapeutic concentrations of drug over several months to years. Implants have been approved as contraceptives in women since 1983 in Finland and 1991 in the US [5,6]. They are now being developed for HIV PrEP by several research laboratories and organizations [6]. For example, Merck's implant formulation of Islatravir, a highly potent nucleoside reverse transcriptase translocation inhibitor (NRTTI), delivered intracellular concentrations above the expected protective threshold in humans for 12 weeks and is estimated to last $>1$ year.

Efforts toward the development of tenofovir alafenamide (TAF) implants have been motivated, in part, by the successful implementation of the class of nucleotide reverse transcriptase inhibitor (NRTI) drugs for HIV treatment and PrEP. NRTI tenofovir (TFV) was the first antiretroviral compound used to demonstrate the efficacy of HIV PrEP in the macaque model [7,8]. TFV is phosphorylated to the active metabolite tenofovir diphosphate (TVF-DP) intracellularly, where it competes with 2'-deoxyadenosine triphosphate (dATP) and inhibits HIV-1 reverse transcriptase [9]. When administered orally, however, TFV had low bioavailability and poor cellular membrane permeability, which prompted subsequent efforts to develop prodrug forms of TFV to address these issues. Tenofovir disoproxil fumarate (TDF), the first generation prodrug of TFV, was approved for HIV treatment as Viread ${ }^{\circledR}$ in 2001 and then for treatment and prevention in combination with emtricitabine as Truvada ${ }^{\circledR}$ in 2012. The second generation prodrug, TAF, a phosphoramidate of TFV, was approved for HIV treatment as the fixed-dose combination Genvoya ${ }^{\circledR}$ in 2015 and more recently for prevention as Descovy ${ }^{\circledR}$ for at-risk adult and adolescent males. Compared to TDF, TAF is better suited for long-acting implants due to its superior potency [9-12], improved safety profile [13] and higher chemical stability at higher $\mathrm{pH}$ [14]. However, as a prodrug, TAF also possess the inherent hydrolytic instability of TDF and is particularly susceptible to acid hydrolysis [14]. Thus, retaining the stability of TAF under physiological condition over extended duration is essential for its application in long-acting delivery systems.

Several long-acting TAF implants are being developed for HIV PrEP, in the preclinical phase, where one is scheduled to begin Phase I/II human studies imminently [15-20]. In particular, Northwestern University described the safety, pharmacokinetics $(\mathrm{PK})$ and manufacturing of a $\mathrm{TAF}_{\mathrm{HF}}$ reservoir implant made of a permeable medical-grade polyurethane membrane with heat-sealed ends [16,20]. Oak Crest Institute of Science designed a non-permeable reservoir implant, made from medical grade-silicone, with delivery channels punched along the length of the device for $\mathrm{TAF}_{\mathrm{FB}}$ to diffuse out [15]. This implant, called OCIS-001, is poised to be studied in a Phase I/II trial (PACTR201809520959443). The Houston Methodist Research Institute evaluated a nanochannel delivery implant (NDI) formed from a medical-grade titanium reservoir plugged with a silicone membrane housing a dense organized array of slit-nanochannels [17,21,22]. At RTI we are developing a biodegradable reservoir implant comprised of poly( $\varepsilon$-caprolactone) (PCL) for HIV PrEP. TAF has served as a model active pharmaceutical ingredient (API) for the platform and has demonstrated controlled release via tunning the surface area, thickness and molecular weight (MW) of the implant wall [18]. We have recently demonstrated zero-order delivery of $\mathrm{TAF}_{\mathrm{FB}}$ over 6 months in-vitro and in vivo from biodegradable implants comprised of poly(E-caprolactone) (PCL) [23].

Herein, we present advancements in the performance of a biodegradable implant for sustained delivery of TAF. We explore how the TAF ionization form $\left(\mathrm{TAF}_{\mathrm{FB}}\right.$ and $\left.\mathrm{TAF}_{\mathrm{HF}}\right)$ along with the excipient type affects the performance of the implants, including in-vitro release rates and chemical stability of various TAF formulations. We demonstrate that $\mathrm{TAF}_{\mathrm{FB}}$ outperforms $\mathrm{TAF}_{\mathrm{HF}}$ within the reservoir-style implant by maintaining higher chemical stability under both simulated physiological and storage conditions. We assess the degradation profiles of $\mathrm{TAF}_{\mathrm{FB}}$ and $\mathrm{TAF}_{\mathrm{HF}}$ formulations and identified the predominant hydrolytic degradants of TAF. We attribute the degradation rate of TAF to be 
$\mathrm{pH}$-dependent and inversely correlated to the rate of water ingress. Devices with thicker PCL walls are used to delay the hydrolysis of TAF within our implants. As a result, we did achieve a high level of TAF purity after 240-days of in-vitro exposure. This manuscript supports the continued advancement of new long-acting delivery systems to address HIV PrEP.

\section{Materials and Methods}

\subsection{Solubility and Stability Screens}

TAF freebase $\left(\mathrm{TAF}_{\mathrm{FB}}\right)$ and TAF hemifumarate salt $\left(\mathrm{TAF}_{\mathrm{HF}}\right)$ were graciously provided by Gilead Sciences (Foster City, CA, USA). Excipients Ethyl Oleate ES45252, Oleic Acid SR40211, Poloxamer 124 Synperonic PE/L 44 ETK1159, Castor Oil SR40890 (CO), Sesame Oil SR40294 (SO), Cottonseed Oil SR40166, PEG40 Castor Oil Etocas 40-SS-(MH)ET48333, PEG300 SR41329, PEG400 SR40377, PEG600 SR40269 (PEG600), Polysorbate 80SR48833, Propylene Glycol SR40836 were sourced from Croda (Snaith, UK) and Glycerol (catalog \# G6279) was sourced from Sigma (St. Louis, MO, USA).

Excess $\mathrm{TAF}_{\mathrm{FB}}(\sim 40 \mathrm{mg})$ was mixed with neat excipient $(\sim 1 \mathrm{~mL})$ in a $20 \mathrm{~mL}$ scintillation vial. Similarly, excess $\mathrm{TAF}_{\mathrm{HF}}(\sim 30 \mathrm{mg})$ was mixed with excipient $(\sim 0.4 \mathrm{~mL})$. Each excipient mixture was incubated at $37^{\circ} \mathrm{C}$ over a period of 2 days, after which the concentration of $\mathrm{TAF}_{\mathrm{FB}}$ or $\mathrm{TAF}_{\mathrm{HF}} \mathrm{was}$ measured by high-performance liquid chromatography (HPLC) to determine the solubility of the API. To determine the stability of the API, the excipient mixtures were prepared as specified above and incubated at $37^{\circ} \mathrm{C}$ for an additional 7 days prior to being analyzed by HPLC.

\subsection{Implant Fabrication}

Research-grade PCL pellets were purchased from Sigma Aldrich, referred to as "Sigma-PCL" throughout this paper (weight average molecular weight $\left(M_{\mathrm{W}}\right)=103 \mathrm{kDa}$, Cat\# 440744, St. Louis, $\mathrm{MO}, \mathrm{USA}$ ) and in medical-grade from Corbion, referred to as "PC17" throughout this paper (average $M_{\mathrm{n}}=93 \mathrm{kDa}$, PURASORB PC 17, Amsterdam, The Netherlands). PCL tubes were fabricated via a hot-melt, single screw extrusion process using solid PCL pellets at GenX Medical (Chattanooga, TN, USA). All tubes were $2.5 \mathrm{~mm}$ in outer diameter (OD) and had wall thicknesses of 70, 100, 150, 200 or $300 \mu \mathrm{m}$, as measured with a 3-axis laser measurement system and light microscopy at GenX Medical.

PCL tubes were sealed at both ends using injection sealing wherein the PCL tube was marked and trimmed to the correct length to achieve an implant with a $40 \mathrm{~mm}$ paste length with $3 \mathrm{~mm}$ of headspace at both ends for sealing. The initial seal was then created on one end of the implant by placing the tube over a stainless steel rod that filled all the tube except for a $3 \mathrm{~mm}$ headspace at one end, placing a Teflon collar around the headspace to support the tube wall and injecting molten PCL into the cavity of the headspace. After the injected PCL was solidified, excess PCL was trimmed and the collar was removed to form a cylindrical seal approximately $2 \mathrm{~mm}$ long that is compatible with commercial contraceptive trocars.

$\mathrm{TAF}_{\mathrm{FB}}$ and $\mathrm{TAF}_{\mathrm{HF}}$ were mixed with excipients at varying mass ratios prior to loading into the implant. Each mixture was first ground with a mortar and pestle to create a smooth paste and then backloaded into a $1 \mathrm{~mL}$ syringe fitted with a 14-gauge blunt tip needle. The TAF formulation was then extruded through the needle into the empty tube. Alternatively, the TAF formulation was loaded into the PCL tube using a modified spatula. After the filled formulation reached the 40-mm mark, the interior tube wall was cleaned with a rod and sealed in a similar manner to the first seal. After fabrication, all implants were weighed to determine the total payload and photographed with a ruler to record the final dimensions. Paste area was measured with ImageJ (Version 1.50e, National Institutes of Health (NIH), Bethesda, MD, USA) and release rates were normalized to the surface area of a full-sized implant (2.5 mm OD, $40 \mathrm{~mm}$ in length), $314 \mathrm{~mm}^{2}$. The end of the implants (i.e., end-seals) were not included in calculations of the implant surface area. 


\subsection{Implant Sterilization}

All implants were fabricated and handled under aseptic conditions using a biosafety cabinet. Certain implants were exposed to gamma irradiation, as indicated in the text. Implants exposed to gamma irradiation were first packed in amber glass vials and then irradiated with a dose range of 18-24 kGy at room temperature, using a Cobalt-60 gamma-ray source (Nordion Inc., Ottawa, ON, Canada) at Steris (Mentor, OH, USA). Samples were exposed to the source on a continuous path for a period of $8 \mathrm{~h}$.

\subsection{In Vitro Release Studies}

In vitro release characterization involved incubation of the implants in $40 \mathrm{~mL} 1 \mathrm{X}$ phosphate buffered saline (PBS) ( $\mathrm{pH} \mathrm{7.4)}$ at $37^{\circ} \mathrm{C}$ and placed on an orbital shaker. TAF species in the release media was measured by ultraviolet-visible (UV) spectroscopy at $260 \mathrm{~nm}$ using the Synergy MX multi-mode plate reader (BioTek Instruments, Inc, Winooski, VT, USA). The release buffer was sampled three times per week during which the implants were transferred to $40 \mathrm{~mL}$ of fresh buffer to maintain sink conditions. TAF quantity released in each PBS buffer during the time interval was calculated and cumulative mass of drug release as a function of time was determined. All the in-vitro release and stability studies have sample sizes of 20 implants, unless noted otherwise. At defined timepoints, 2 devices were taken down to determine chromatographic purity of TAF and water content inside the implant reservoir.

\subsection{Stability Analysis of TAF Formulation}

The purity of TAF formulations inside the implant reservoir was evaluated by slicing open an implant, extracting the entire reservoir contents into an organic solution and measuring TAF chromatographic purity using high performance liquid chromatography coupled with UV spectroscopy (HPLC/UV). The analysis was performed using a Waters BEH C18 column $(2.1 \mathrm{~mm} \times 50 \mathrm{~mm}, 1.7 \mu \mathrm{m})$ under gradient, reversed phase conditions with detection at $260 \mathrm{~nm}$. Shelf stability implants containing $\mathrm{TAF}_{\mathrm{FB}}$ formulations were analyzed using an Agilent Zorbax column $(4.6 \mathrm{~mm} \times 150 \mathrm{~mm}, 3.5 \mu \mathrm{m})$. For each implant, one single aliquot was prepared and quantitated by linear regression analysis against a five-point calibration curve. TAF purity was calculated as \% peak area associated with TAF relative to total peak area of TAF related degradation products (detected above the limit of detection (LOD) $\geq 0.05 \%$ ). The TAF formulations within the implant were analyzed after exposure of the implant to a simulated physiological condition (i.e., $1 \mathrm{X} \mathrm{PBS}$, pH 7.4 at $37^{\circ} \mathrm{C}$ ) for up to 240 days. A scalpel was used to slit the implants lengthwise and the contents of the scalpel were blotted on $\mathrm{pH}$ paper to assess the $\mathrm{pH}$ within the device core.

\subsection{Loss on Drying Analysis}

A glass-stoppered, shallow weighing bottle was placed in the vacuum oven at $40{ }^{\circ} \mathrm{C}$ for $30 \mathrm{~min}$, cooled to room temperature and weighed $\left(W_{\text {bottle }}\right)$. Retrieved implants from each timepoint were placed in individual bottles and their weight was recorded $\left(W_{w}\right)$ and placed in the vacuum oven at $40{ }^{\circ} \mathrm{C}$ overnight (the glass stopper was removed from the bottle but left in the vacuum oven as well). The glass bottle was closed prior to weighing it with the implant $\left(W_{d}\right)$. This process was repeated until the new recorded weight $\left(W_{d}^{\prime}\right)$ was within $0.1 \mathrm{mg}$ of $W_{d}$. The implant loss on drying (i.e., the amount of water content that was present in the implant) was calculated using the following equation:

$$
\% \text { Loss on drying }=\frac{W_{w}-W_{d}^{\prime}}{W_{w}-W_{\text {bottle }}} \times 100
$$




\subsection{Shelf Stability}

Implant filled with $\mathrm{TAF}_{\mathrm{FB}}$ and $\mathrm{TAF}_{\mathrm{HF}}$ formulations were placed in aluminum foil pouches. Half of the pouches were sealed using an impulse heat sealer (AIE-110T, American International Electric Inc., Industry, CA, USA), while the remaining ones were left unsealed. The sealed pouches containing the implants were further split into two groups: stored under ambient conditions and in an incubator at $37^{\circ} \mathrm{C}$ with $40 \%$ relative humidity (RH). The same was repeated for the unsealed pouches containing the TAF formulation implants. The implants were removed from the pouches and assessed for purity using HPLC at the following timepoints: 0, 90, 180 days. Note: the implants containing TAF $_{\mathrm{HF}}$ formulations were sterilized at $>40 \mathrm{kGy}$ using the same parameters as specified in Section 2.3.

\subsection{Differential Scanning Calorimetry (DSC)}

The melting behavior of PCL samples was assessed with modulated differential scanning calorimetry (MDSC) (TA Instruments Q200, RCS90 cooling system, New Castle, DE, USA). Approximately $8 \mathrm{mg}$ of extruded polymer tubing was placed in a Tzero ${ }^{\mathrm{TM}} \mathrm{Pan}$ and sealed with a Tzero ${ }^{\mathrm{TM}} \mathrm{Lid}$ and a dome-shaped die, resulting in a crimped seal. Samples were then placed in a nitrogen-purged DSC cell, cooled to $0^{\circ} \mathrm{C}$, then heated to $120^{\circ} \mathrm{C}$ at a rate of $1^{\circ} \mathrm{C} / \mathrm{min}$ with an underlying heat-only modulation temperature scan of $\pm 0.13^{\circ} \mathrm{C}$ every $60 \mathrm{~s}$. The melting temperature $\left(T_{m}\right)$ of the polymer was determined by the peak temperature of the melting endotherm and the enthalpy associated with melting was determined by integrating linearly the area of the melt peak (between 25 and $65^{\circ} \mathrm{C}$ ) using the TA Universal Analysis software (version 4.5A, TA Instruments, New Castle, DE, USA). PCL samples did not exhibit exothermic peaks in the non-reversing heat flow signal indicating that PCL did not experience cold-crystallization during the melting process; therefore, the total heat flow curve was used to assess the mass $\%$ crystallinity. The mass $\%$ crystallinity was calculated using the following equation, where $X_{c}$ represents the mass fraction of crystalline domains in PCL, $\Delta H_{m}$ represents the enthalpy of melting measured by the DSC and $\mathrm{xH}_{f u s}$ represents the theoretical enthalpy of melting for $100 \%$ crystalline PCL, reported as $139.5 \mathrm{~J} / \mathrm{g}$ [24,25].

$$
X_{C}=\frac{\Delta H_{m}}{\Delta H_{f u s}} \times 100 .
$$

\subsection{Gel Permeation Chromatography (GPC)}

The MW of PCL was analyzed via GPC by first dissolving samples in tetrahydrofuran (THF) to $10 \mathrm{mg} / \mathrm{mL}$ injecting $40 \mu \mathrm{L}$ of sample using an Agilent 1100/1200 HPLC-UV instrument (Santa Clara, CA, USA, flow rate of $1.0 \mathrm{~mL} / \mathrm{min}$ ). Polystyrene polymer standards ( $498 \mathrm{Da}$ to $554 \mathrm{kDa}$ ) were used to calibrate the MW of samples.

\section{Results and Discussion}

\subsection{In Vitro Performance of $P C L$ Reservoir Implants with $T A F_{H F}$ and $T A F_{F B}$ Formulations}

In this study, we investigated various TAF formulations within a biodegradable implant under simulated physiological conditions. The implant configuration comprises a reservoir of formulated API encapsulated by a biodegradable PCL membrane (Figure 1). The implants were fabricated from PCL tubes produced via a hot-melt, single screw extrusion process using solid PCL pellets, with an outer diameter (OD) of $2.5 \mathrm{~mm}$ and a length of $40 \mathrm{~mm}$. Implants containing TAF in solid form with no additional excipients were first evaluated under in-vitro conditions that mimic physiological environments. Implants containing only TAF exhibited non-linear release profiles (see Figure S1), likely a consequence of the dissolution process of solid TAF within the reservoir and the lack of PCL membrane-controlled release of drug. Therefore an excipient was incorporated into the API formulation to tailor dissolution rates. We conducted a screening study with several excipients identified from the FDA's inactive ingredient list. The excipient screen involved mixing $\mathrm{TAF}_{\mathrm{FB}}$ or $\mathrm{TAF}_{\mathrm{HF}}$ with various 
excipients and incubating the mixtures at $37^{\circ} \mathrm{C}$. The solubility and stability of each TAF form within the pharmaceutical grade excipients were determined by a HPLC method after 2 or 9 days of incubation, respectively (Table 1). Lead excipients were identified for each API with criteria of showing $<3 \%$ impurity level. Sesame oil and castor oil were therefore down-selected for TAF $F_{F B}$. Besides the castor oil, a poly(ethylene glycol) (PEG) excipient was also considered for $\mathrm{TAF}_{\mathrm{HF}}$, because of a high $\mathrm{TAF}_{\mathrm{HF}}$ stability reported by Schlesinger et al., within the thin-film polymer implants [26]. We selected PEG600 as an excipient for $\mathrm{TAF}_{\mathrm{HF}}$, due to its larger molecular weight as compared to other PEG excipients of shorter chain length (i.e., PEG300, PEG400).

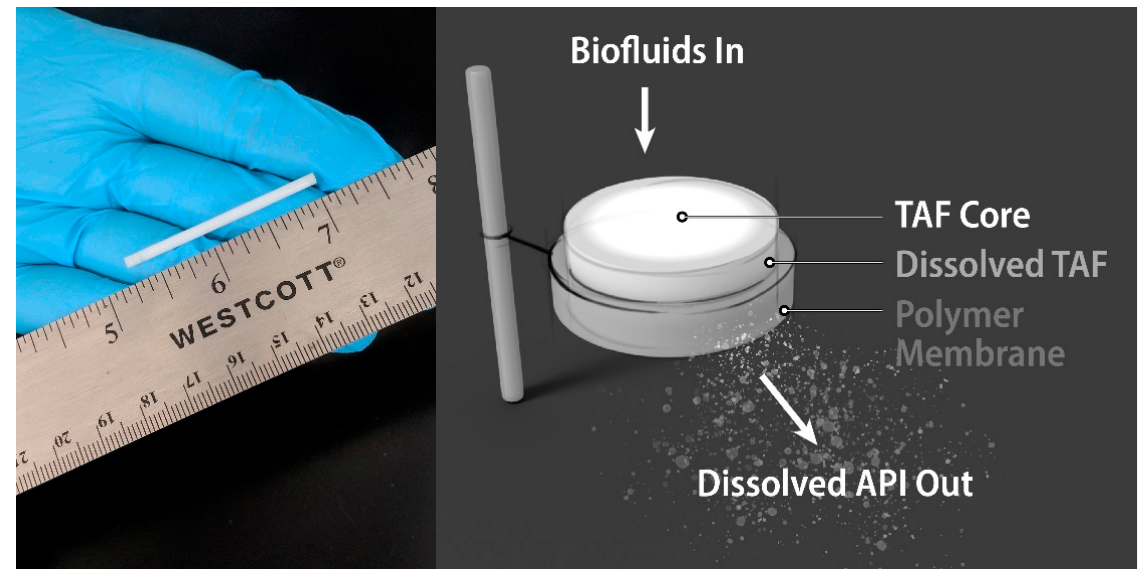

Figure 1. (Left) A digital camera image of the biodegradable implant. (Right) A schematic of a poly( $\varepsilon$-caprolactone) (PCL) reservoir-style implant for sustained delivery of tenofovir alafenamide (TAF) formulations.

Table 1. The solubility and chromatographic impurity of $\mathrm{TAF}_{\mathrm{FB}}$ and $\mathrm{TAF}_{\mathrm{HF}}$ within various pharmaceutical grade excipients identified in the FDA's inactive ingredient list.

\begin{tabular}{ccccc}
\hline Excipients & $\begin{array}{c}\text { TAF }_{\mathbf{H F}} \text { Solubility } \\
\mathbf{( m g / m L )}\end{array}$ & $\begin{array}{c}\text { TAF }_{\mathbf{H F}} \text { \% Impurities } \\
\text { at Day-9 }\end{array}$ & $\begin{array}{c}\text { TAF }_{\mathrm{FB}} \text { Solubility } \\
\mathbf{( m g} / \mathbf{m L})\end{array}$ & $\begin{array}{c}\text { TAF }_{\mathrm{FB}} \text { \% Impurities } \\
\text { at Day-9 }\end{array}$ \\
\hline Castor Oil & 12.4 & 1.1 & 16.5 & 2.3 \\
Sesame Oil & 0.34 & 8.2 & 0.06 & 2.1 \\
PEG600 & 57.6 & 18.5 & 56.8 & 7.2 \\
API only & - & 4.4 & - & 1.9 \\
API exposed to $37^{\circ} \mathrm{C}$ & - & 4.4 & - & 2.0 \\
\hline
\end{tabular}

After selection of the excipients, we conducted an in-vitro study to assess the release kinetics and the chromatographic purity of $\mathrm{TAF}_{\mathrm{HF}}$ and $\mathrm{TAF}_{\mathrm{FB}}$ within the reservoir over time when implants were immersed in aqueous, physiologically relevant conditions $\left(\mathrm{pH}=7.4,37^{\circ} \mathrm{C}\right)$. $\mathrm{TAF}_{\mathrm{HF}}$ and $\mathrm{TAF}_{\mathrm{FB}}$ were first formulated with the lead excipients at a mass ratio of 2:1 and loaded in the PCL extruded tubes (100 $\mu \mathrm{m}$ wall thickness) comprising PCL with $M_{\mathrm{w}}$ of $145 \mathrm{kDa}$. Table 2 shows the formulation, TAF payload and configuration of tested implants. The cumulative release profiles for various TAF formulations are shown in Figure 2. All implants exhibited a period of zero-order drug release. $\mathrm{TAF}_{\mathrm{FB}}$ implants exhibited linear release with a constant release rate of TAF species (non-degraded TAF and tenofovir-containing species) over 210 days, while the TAF $\mathrm{HF}_{\mathrm{implants}}$ demonstrated zero-order release of TAF species up to 120 days. The drug release rates for implant containing formulations with TAF $_{\mathrm{HF}}$ and PEG600 exhibited relatively large variations and deviated from zero-order release near day 90, which was likely attributed to the swelling of the implants. This swelling behavior was previously observed for other hydrophilic excipients (i.e., glycerol, PEG300, PEG400) due to the high-water solubility, which leads to high osmotic pressure within the implant core. The average release rates for $\mathrm{TAF}_{\mathrm{HF}}-\mathrm{CO}$ formulation and $\mathrm{TAF}_{\mathrm{HF}}-\mathrm{PEG} 600$ formulation were $0.38 \pm 0.04 \mathrm{mg} / \mathrm{day}$ and $0.68 \pm 0.20 \mathrm{mg} /$ day, respectively. $\mathrm{TAF}_{\mathrm{FB}}$ formulations exhibited lower release rates than the TAF $\mathrm{HF}$ 
formulations, with average release rates of $0.26 \pm 0.04 \mathrm{mg} / \mathrm{day}$ and $0.18 \pm 0.03 \mathrm{mg} / \mathrm{day}$ for castor oil and sesame oil formulation, respectively. The differences in release rates between implants containing $\mathrm{TAF}_{\mathrm{HF}}$ and $\mathrm{TAF} F \mathrm{FB}$ are likely related to the solubility of these APIs within the excipients and PBS buffer, since $\mathrm{TAF}_{\mathrm{HF}}$ showed a higher solubility within PBS $(11.6 \mathrm{mg} / \mathrm{mL})$ than $\mathrm{TAF}_{\mathrm{FB}}(5.8 \mathrm{mg} / \mathrm{mL})$. In addition, the $\mathrm{TAF}_{\mathrm{FB}}-\mathrm{CO}$ formulation demonstrated a faster release rate than the $\mathrm{TAF}_{\mathrm{FB}}-\mathrm{SO}$ implants, which is also likely attributed to the higher solubility of the TAF $F_{F B}$ within castor oil. According to Fick's first law of diffusion, the release rate is directly proportional to the drug concentration gradient across the PCL membrane, which is equivalent to the solubility of API within the excipients when zero-order release kinetics is achieved [27]. As shown in Table 1, TAF ${ }_{\mathrm{FB}}$ showed higher solubility within castor oil than sesame oil, resulting in higher release rates. Similarly, the TAF $\mathrm{HF}_{\mathrm{F}}-\mathrm{PE} 600$ formulation demonstrated a faster release rate than the $\mathrm{TAF}_{\mathrm{HF}}-\mathrm{CO}$ implants, which is likely attributed to the higher solubility of the $\mathrm{TAF}_{\mathrm{HF}}$ within PEG600.Therefore, the release rate of the implant is dictated by the solubility of the API within the selected excipients and the release media. The excipient choice is critical for tuning the release rate of TAF.

Table 2. The formulation and PCL membrane configuration for tested implants.

\begin{tabular}{ccccccc}
\hline Formulations & API & Excipient & $\begin{array}{c}\text { Wall Thickness } \\
(\boldsymbol{\mu m})\end{array}$ & $\begin{array}{c}\text { Length of } \\
\text { Implant }(\mathbf{m m})\end{array}$ & $\begin{array}{c}\text { PCL } \boldsymbol{M}_{\mathbf{w}} \\
(\mathbf{k D a})\end{array}$ & $\begin{array}{c}\text { Approximate } \\
\text { TAF Payload }(\mathbf{m g})\end{array}$ \\
\hline $\mathrm{TAF}_{\mathrm{HF}}-\mathrm{CO}$ & $\mathrm{TAF}_{\mathrm{HF}}$ & Castor oil & & & & 120 \\
$\mathrm{TAF}_{\mathrm{HF}}-\mathrm{PEG600}$ & $\mathrm{TAF}_{\mathrm{HF}}$ & PEG600 & 100 & 40 & 145 & 122 \\
$\mathrm{TAF}_{\mathrm{FB}}-\mathrm{CO}$ & $\mathrm{TAF}_{\mathrm{FB}}$ & Castor oil & & & & 118 \\
$\mathrm{TAF}_{\mathrm{FB}}-\mathrm{SO}$ & $\mathrm{TAF}$ & Sesame oil & & & & 113 \\
\hline
\end{tabular}

(a)

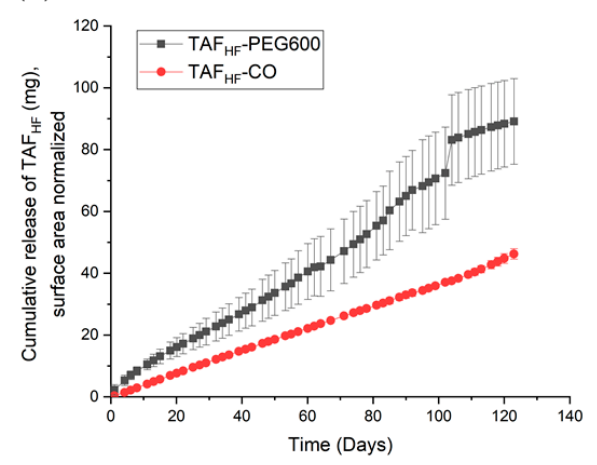

(b)

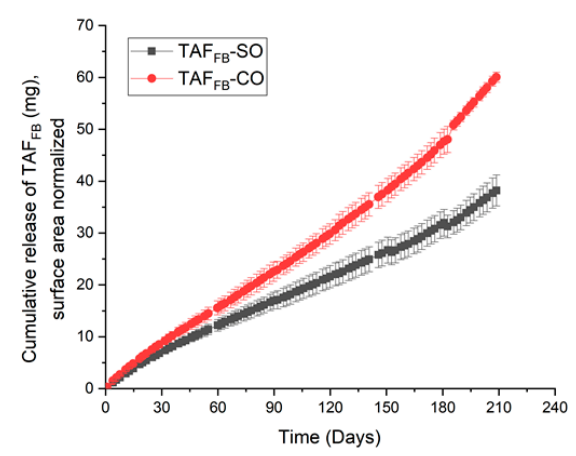

Figure 2. Cumulative release profiles of various $\operatorname{TAF}_{\mathrm{HF}}(\mathbf{a})$ and $\operatorname{TAF}_{\mathrm{FB}}(\mathbf{b})$ formulations.

\subsection{In Vitro Stability Assessment of Implant Formulations}

To evaluate the degradation profiles of $\mathrm{TAF}_{\mathrm{HF}}$ and $\mathrm{TAF}_{\mathrm{FB}}$ inside the reservoir of implants exposed to PBS at $37^{\circ} \mathrm{C}$, implants were periodically removed from the study and sacrificed to assess the stability of TAF using HPLC analysis. Figure $3 a, b$ shows the chromatographic purity of TAF HF $_{\text {in }}$ the reservoir of implants over 120 days. By day 120, the purity of $\mathrm{TAF}_{\mathrm{HF}}$ decreased from $99.8 \%$ to $17.6 \%$ for $\mathrm{TAF}_{\mathrm{HF}}-\mathrm{CO}$ formulations and from $99.7 \%$ to $1.36 \%$ for $\mathrm{TAF}_{\mathrm{HF}}-\mathrm{PEG} 600$ formulations (raw data shown in Table S1). These results show that $\mathrm{TAF}_{\mathrm{HF}}-\mathrm{CO}$ formulations exhibit a higher degree of stability than the TAF $\mathrm{HF}_{\mathrm{PEG}}$-P00 formulations after exposure to simulated physiological conditions, which is consistent with the stability results from the excipient screen. It is reasonable to expect that $\mathrm{TAF}_{\mathrm{HF}}-\mathrm{PEG600}$ formulation degrades at a faster rate given the hydrophilicity of PEG600. In comparison, the chromatographic purity of $\mathrm{TAF}_{\mathrm{FB}}$ formulations was also monitored using the HPLC method. Results are shown in Figure 3c,d and raw data are listed in Table S2. Unlike TAF $F_{H F}$ formulations, a high level of purity was achieved for $\mathrm{TAF}_{\mathrm{FB}}$ formulations at 210 days. The TAF $\mathrm{FB}-\mathrm{SO}$ formulation demonstrated a slightly higher purity $(92 \%)$ than that of $\mathrm{TAF}_{\mathrm{FB}}-\mathrm{CO}$ formulations $(85 \%)$ at 210 days, which is in a good agreement with the excipient screen results. 
(a)

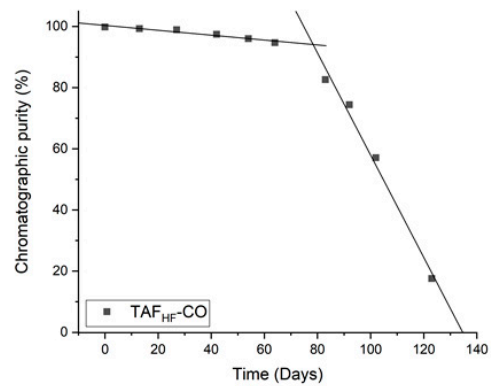

(c)

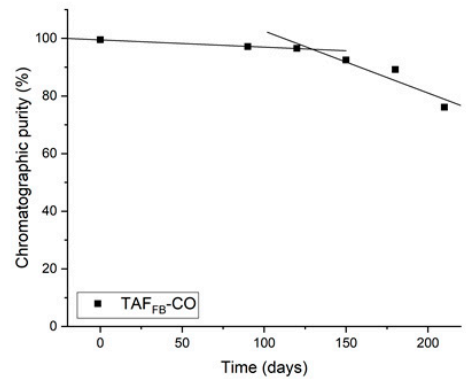

(b)

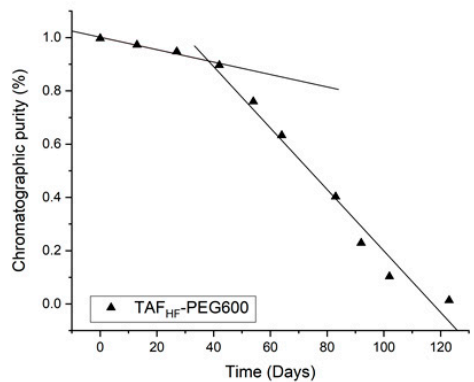

(d)

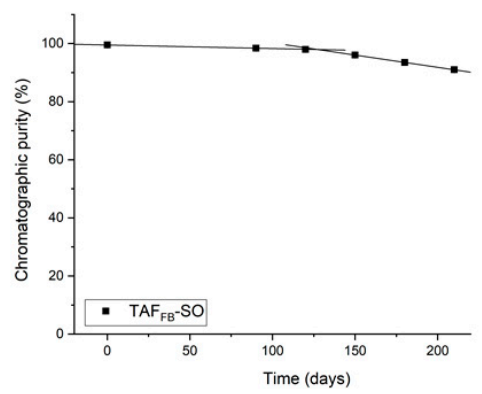

Figure 3. Degradation profiles of $\operatorname{TAF}_{\mathrm{HF}}(\mathbf{a}, \mathbf{b})$ and $\operatorname{TAF}_{\mathrm{FB}}(\mathbf{c}, \mathbf{d})$ formulations within implants with a wall thickness of $100 \mu \mathrm{m}$ after exposure to simulated physiological conditions $\left(37^{\circ} \mathrm{C}\right.$, PBS). The fits (black lines) correspond to a two-line model for each formulation.

Irrespective of the formulation, TAF within the implants remained unhydrolyzed and chemically stable within the implant at the beginning of the in-vitro study, then reached a point in time when the degradation rate accelerated. These results are consistent with our hypothesis of a two-stage degradation profile of TAF, where TAF in the solid-state remains relatively stable and then hydrolyzes to TAF degradants once solid TAF dissolves in aqueous solutions. To assess the degradation rate constants for the initial and accelerated stages, the chromatographic purity of TAF was plotted as a function of time and a two-line model was applied to depict the non-linear degradation profiles of various TAF formulations. Excellent fits to the experimental data were obtained $\left(R^{2}>0.94\right.$ for all the fittings, see Figure 3). The two-line model also identified the inflection point of these degradation profiles, which represents the point in time when accelerated degradation of TAF begins.

As expected, $\mathrm{TAF}_{\mathrm{HF}}-\mathrm{PEG} 600$ formulation exhibited a higher initial rate of degradation with an early inflection point at $\sim 38$ days, compared to $\sim 78$ days for $\mathrm{TAF}_{\mathrm{HF}}-\mathrm{CO}$ formulation. Furthermore, the two-line models can project the purity of $\mathrm{TAF}_{\mathrm{HF}}$ along the time axis for these specific formulations. It is predicted that $\mathrm{TAF}_{\mathrm{HF}}$ would be completely hydrolyzed and depleted within the $100 \mu \mathrm{m}$ thick implants with the $\mathrm{TAF}_{\mathrm{HF}}-\mathrm{CO}$ formulation after exposure to the in-vitro environment for $\sim 140$ days. In contrast, $\mathrm{TAF}_{\mathrm{FB}}$ formulations exhibited a lower rate of degradation with a delayed onset of the accelerated degradation phase ( 130 days). Based on the model, the $\mathrm{TAF}_{\mathrm{FB}}-\mathrm{SO}$ and $\mathrm{TAF}_{\mathrm{FB}}-\mathrm{CO}$ formulations can maintain $>90 \%$ purity for up to 220 days and 155 days, respectively. In particular, the $\mathrm{TAF}_{\mathrm{FB}}-\mathrm{SO}$ formulation showed a lower rate of degradation for both initial and accelerated phases of degradation, as compared to $\mathrm{TAF}_{\mathrm{FB}}-\mathrm{CO}$ formulation. These results indicate that $\mathrm{TAF}_{\mathrm{FB}}$ formulations are more stable than the $\mathrm{TAF}_{\mathrm{HF}}$ formulations under simulated physiological conditions. This is likely attributed to the differences in the hydrolytic instability of $\mathrm{TAF}_{\mathrm{FB}}$ and $\mathrm{TAF}_{\mathrm{HF}}$ formulations within the device cores, as both $\mathrm{TAF}_{\mathrm{FB}}$ and $\mathrm{TAF}_{\mathrm{HF}}$ degrade through hydrolysis [9,14]. Specifically, hydrolytic degradation and pathway of TAF are dependent on the $\mathrm{pH}$ in the implant microenvironment [22]. The degradation rate of TAF increases in basic conditions due to the $\mathrm{P}-\mathrm{O}$ bond in its structure that is prone to hydrolysis in alkaline conditions [28]. In addition, a higher instability of TAF in low-pH conditions is also observed and is likely due to the presence of P-N (phosphoramidate) bond, which particularly is susceptible to acid hydrolysis [29]. Thus, a $\mathrm{pH}$ "stability window" for TAF between $\mathrm{pH} 4.8-5.8$ was determined by Grattoni et al. [22]. To elucidate why $\mathrm{TAF}_{\mathrm{FB}}$ formulations outperformed $\mathrm{TAF}_{\mathrm{HF}}$ formulations within 
our platform, we further measured the $\mathrm{pH}$ of the formulated implant core using $\mathrm{pH}$ paper prior to purity analysis. Both $\mathrm{TAF}_{\mathrm{FB}}$ formulations showed similar $\mathrm{pH}$ levels of $\sim 4-5$ at 210 days, whereas the $\mathrm{pH}$ of residual $\mathrm{TAF}_{\mathrm{HF}}$ formulation inside the device core was $\sim 2-3$ at $\sim 200$ days (data not shown). Implant reservoir loaded with $\mathrm{TAF}_{\mathrm{HF}}$ formulation is expected to have a more acidic environment due to fumaric acid. This explains the low stability of $\mathrm{TAF}_{\mathrm{HF}}$ formulation because lower $\mathrm{pH}$ leads to more rapid TAF degradation.

Besides the $\mathrm{pH}$ level of the microenvironment in the device core, we also hypothesized that a correlation exists between the level of TAF degradation and the amount of water uptake by the implants. Therefore, we measured the water content within the implants using a loss-on-drying method. This approach is adapted from the United States Pharmacopeia (USP) Chapter for Loss-on-Drying, where we compared the weight of an implant before and after it was dried in a vacuum oven at $40^{\circ} \mathrm{C}$ after removal from buffer. The percentage of water content for various TAF formulations was plotted as a function of time (Figure 4). The amount of water ingress at different time points along with the cumulative amounts of drug release at a given time is also listed in Tables S3 and S4. At Day-120, the $\mathrm{TAF}_{\mathrm{HF}}-\mathrm{CO}$ implants gained $\sim 10 \mathrm{mg}$ of water, whereas $\mathrm{TAF}_{\mathrm{HF}}-\mathrm{PEG} 600$ implants gained $\sim 18 \mathrm{mg}$ of water. The significantly large amount of water uptake by the $\mathrm{TAF}_{\mathrm{HF}}-\mathrm{PEG} 600$ implants explains the low levels of chromatographic purity of $\mathrm{TAF}_{\mathrm{HF}}$ inside the implant reservoir. In contrast, $\mathrm{TAF}_{\mathrm{FB}}$ implants measured a much lower percentage of water ingress as compared to $\mathrm{TAF}_{\mathrm{HF}}$ implants at a given time. For instance, the amount of water ingress at 120 days for $\mathrm{TAF}_{\mathrm{FB}}-\mathrm{CO}$ and $\mathrm{TAF}_{\mathrm{FB}}-\mathrm{SO}$ only consists of $\sim 4.6 \%$ and $8.4 \%$ of the total mass of the implants, respectively, which are significantly lower than that of $\mathrm{TAF}_{\mathrm{HF}}-\mathrm{CO}(\sim 11.6 \%)$ and $\mathrm{TAF}_{\mathrm{HF}}-\mathrm{PEG} 600$ implants $(\sim 21.6 \%)$. In addition, $\mathrm{TAF}_{\mathrm{FB}}-\mathrm{SO}$ formulation exhibited a lower level of water ingress than the $\mathrm{TAF}_{\mathrm{FB}}-\mathrm{CO}$ formulation, which is likely due to a lower release rate of the $\mathrm{TAF}_{\mathrm{FB}}-\mathrm{SO}$ formulation. As shown in Table S4, the amount of cumulative drug release for $\mathrm{TAF}_{\mathrm{FB}}-\mathrm{CO}$ formulation is higher than $\mathrm{TAF}_{\mathrm{FB}}-\mathrm{SO}$ formulation at a given time. Although both $\mathrm{TAF}_{\mathrm{FB}}-\mathrm{SO}$ and $\mathrm{TAF}_{\mathrm{FB}}-\mathrm{CO}$ formulation exhibited a comparable $\mathrm{pH}$ level in the implant core ( $\mathrm{pH}$ of $\sim 4-5$ ), higher drug release may create more void space for water to permeate into the implants resulting in faster degradation of $\mathrm{TAF}_{\mathrm{FB}}$. Thus, reducing the release rate of drug from the implants can potentially slow down the rate of water ingress and improve the formulation stability.

(a)

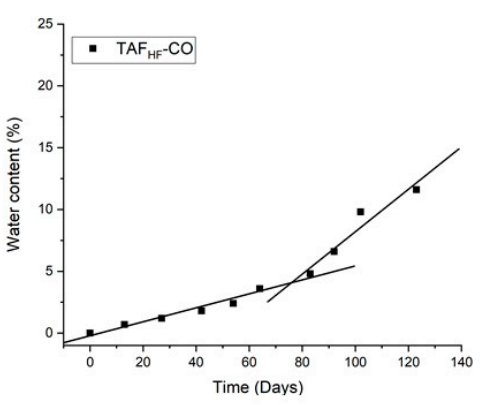

(c)

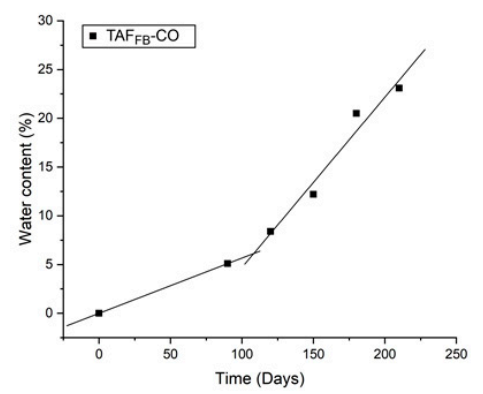

(b)

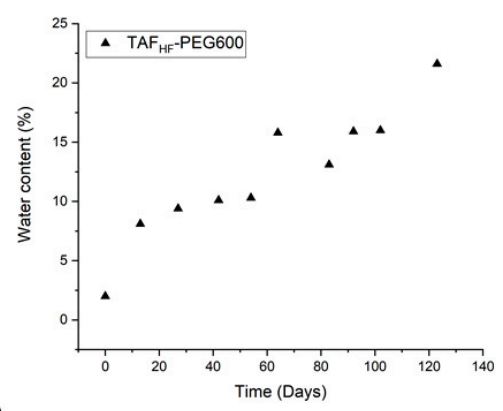

(d)

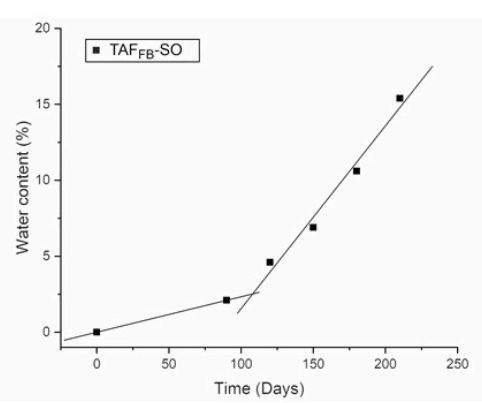

Figure 4. Water ingress profiles of $\mathrm{TAF}_{\mathrm{HF}}-\mathrm{CO}(\mathbf{a}), \mathrm{TAF}_{\mathrm{HF}}-\mathrm{PEG} 600(\mathbf{b}), \mathrm{TAF}_{\mathrm{FB}}-\mathrm{CO}(\mathbf{c})$, and $\mathrm{TAF}_{\mathrm{FB}}-\mathrm{SO}$ (d) formulations within PCL implants exposed to simulated physiological conditions $\left(37^{\circ} \mathrm{C}, \mathrm{PBS}\right)$. Two-line model (depicted in black lines) has been applied to $\mathrm{TAF}_{\mathrm{HF}}-\mathrm{CO}, \mathrm{TAF}_{\mathrm{FB}}-\mathrm{CO}$ and $\mathrm{TAF}_{\mathrm{FB}}-\mathrm{SO}$ formulations in mass ratios of 2:1. 
Similar to the TAF degradation profiles, the water ingress profiles also showed a two-step process, where the amount of water ingress was negligible at the beginning of the study, then increased dramatically at an accelerated rate (Figure 4). To assess the water permeation rates, two-line models were also applied to the water ingress profiles of various formulations. Excellent fits to the water ingress data were obtained for the $\mathrm{TAF}_{\mathrm{HF}}-\mathrm{CO}, \mathrm{TAF}_{\mathrm{FB}}-\mathrm{CO}$ and $\mathrm{TAF}_{\mathrm{FB}}-\mathrm{SO}$ formulations $\left(\mathrm{R}^{2}>0.92\right.$ for all the fitting). Table 3 shows the inflection point for each formulation along with the quantities of drug remaining, TAF purities and water content at the given inflection point. The inflection points in the water ingress profiles closely aligned with those of the degradation profiles, confirming that the TAF purity is correlated with the amount of water ingress. In contrast, the water ingress profile for the TAF $\mathrm{HF}_{\mathrm{F}}-\mathrm{PEG} 600$ implants is sigmoidal and does not fit the two-line models. As a hydrophilic and water-soluble excipient, PEG draws more water into the implant core, resulting in swelling of the implants. Additionally, four $\mathrm{TAF}_{\mathrm{HF}}-\mathrm{PEG} 600$ implants that were subjected to the loss-on-drying analysis were compromised due to swelling, resulting in an artificially higher amount of water ingress. It is worth noting that $\mathrm{TAF}_{\mathrm{FB}}$ formulations at the inflection point ( 130 days) showed higher purity than the $\mathrm{TAF}_{\mathrm{HF}}$ formulations at their inflection points ( 38-78 days) while the percentages of water ingress are comparable for these formulations, indicating that $\mathrm{TAF}_{\mathrm{FB}}$ is less susceptible to hydrolysis as compared to $\mathrm{TAF}_{\mathrm{HF}}$. This is likely due to the differences in the $\mathrm{pH}$ level within the device core as previously discussed.

Table 3. The inflection points determined by fitting the degradation profiles of various TAF formulations to the two-line models. Mass quantities of drug remaining and TAF stability at the inflection points are included.

\begin{tabular}{cccccc}
\hline Formulation & $\begin{array}{c}\text { Inflection } \\
\text { Point (Day) }\end{array}$ & $\begin{array}{c}\text { Drug Remaining at } \\
\text { the Inflection Point }\end{array}$ & $\begin{array}{c}\text { Stability Near the } \\
\text { Inflection Point }\end{array}$ & $\begin{array}{c}\text { Water Content } \\
\text { (mg) Near the } \\
\text { Inflection Point }\end{array}$ & $\begin{array}{c}\text { \% of Water } \\
\text { Ingress Near the } \\
\text { Inflection Point }\end{array}$ \\
\hline $\mathrm{TAF}_{\mathrm{HF}}-\mathrm{CO}$ & 78 & $91.8 \mathrm{mg} / 75.6 \%$ & $93.9 \%$ & 4.0 & $4.8 \%$ \\
$\mathrm{TAF}_{\mathrm{HF}}-\mathrm{PEG} 60$ & 38 & $97.7 \mathrm{mg} / 79.3 \%$ & $91.3 \%$ & 8.4 & $10.1 \%$ \\
$\mathrm{TAF}_{\mathrm{FB}}-\mathrm{CO}$ & 130 & $82.5 \mathrm{mg} / 71.2 \%$ & $96.3 \%$ & 19.6 & $8.4 \%$ \\
$\mathrm{TAF}_{\mathrm{FB}}-\mathrm{SO}$ & 132 & $86.7 \mathrm{mg} / 78.7 \%$ & $97.6 \%$ & 10.0 & $4.6 \%$ \\
\hline
\end{tabular}

We further explored the relationship between the purity of TAF and the water content within these implants. Figure 5 illustrates the purity of TAF and the water content as a function of time for implants containing formulations of $\mathrm{TAF}_{\mathrm{HF}}$ and $\mathrm{TAF}_{\mathrm{FB}}$. Both the TAF degradation and water ingress profiles appear to exhibit a two-stage process. For example, the purity of formulated $\mathrm{TAF}_{\mathrm{HF}}$ inside the implant reservoir decreases at an accelerated rate after $\sim 80$ days in-vitro, while the rate of water ingress also increases after the same time (see Figure 5a). Similar degradation behaviors were observed for $\mathrm{TAF}_{\mathrm{FB}}$ around $\sim 130$ days for both castor oil and sesame oil formulations (Figure $5 \mathrm{~b}$ ). This data suggests that the predominant reason for accelerated TAF degradation is related to water ingress, wherein the accumulation of water within the reservoir accelerates the rate of TAF hydrolysis. In addition, the increasing concentration of TAF degradants within the implant core could in turn draw a larger amount of water into the implant, as the most prominent TAF degradants (e.g., tenofovir, monophenyl-TFV) are hydrophilic and/or water-soluble. A possibility also exists that the increased concentration of solute resulting from the breakdown of TAF creates an osmotic gradient as a driving force for water to imbibe into the implant core. Taken together, the degradation of TAF is caused by water ingress and the resultant degradation products may accelerate the rate of water permeation. Thus, a strong correlation between TAF impurity and water content within the implants was established. To summarize, as the degradation of TAF is dependent on the $\mathrm{pH}$ and amount of water ingress, implants containing the $\mathrm{TAF}_{\mathrm{FB}}-\mathrm{SO}$ formulations showed a $\mathrm{pH}$ level within the "stability window" that substantially mitigates the TAF degradation and a relatively low release rate that slows down the rate of water ingress. Therefore, $\mathrm{TAF}_{\mathrm{FB}}-\mathrm{SO}$ formulations were identified as the lead formulation for the sustained delivery of TAF within our biodegradable drug delivery platform. 
(a)

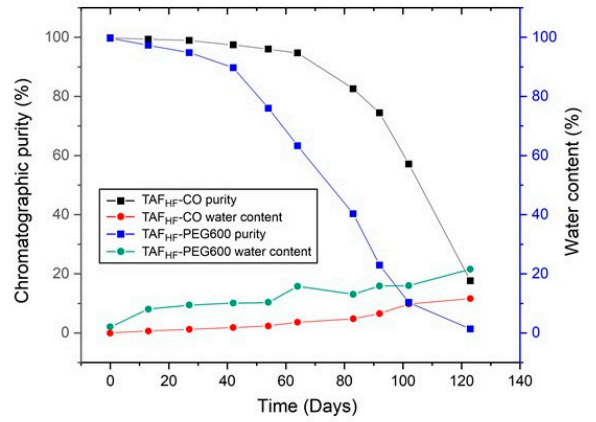

(b)

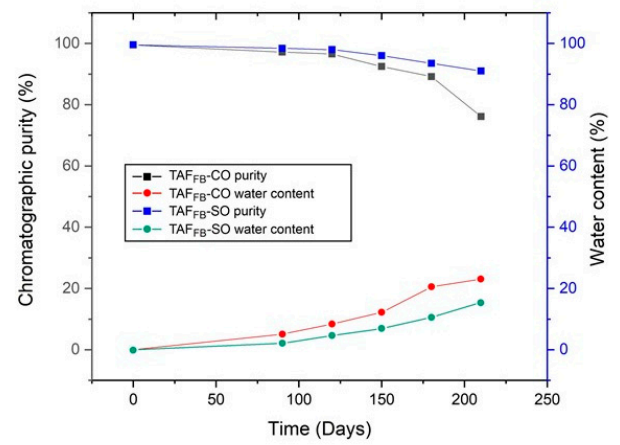

Figure 5. TAF purity and water uptake for the $\mathrm{TAF}_{\mathrm{HF}}$ implants $(\mathbf{a})$ and $\mathrm{TAF}_{\mathrm{FB}}$ implants $(\mathbf{b})$ as a function of time.

\subsection{Hydrolytic Degradants of TAF}

In addition to assessing the chromatographic purity of TAF, individual TAF degradants $>0.05 \%$ were identified using known markers on HPLC with confirmation by liquid-chromatography mass spectrometry (LC-MS) at the relative retention time (RRT). Figure 6 shows the levels of individual degradants as a function of time for various TAF formulations. All degradants detected in the implant resulted from the hydrolysis of TAF, with the predominant species including TFV (the parent API) and monophenyl-TFV (an intermediate in the TAF hydrolytic pathway) for all formulations. These two degradants were measured at comparable levels within the $\mathrm{TAF}_{\mathrm{FB}}-\mathrm{CO}, \mathrm{TAF}_{\mathrm{FB}}-\mathrm{SO}$ and $\mathrm{TAF}_{\mathrm{HF}}-\mathrm{CO}$ implants, whereas the TAF $\mathrm{HF}_{\mathrm{F}} \mathrm{PEG} 600$ implants contained a significantly higher level of monophenyl-TFV than TFV. The higher amount of monophenyl-TFV within the $\mathrm{TAF}_{\mathrm{HF}}$-PEG600 implant is likely related to a larger amount of water ingress resulting from the compromised integrity of the implant. The observed TAF degradants are well-aligned with the degradation products in acid solution state reported in the literature. Figure 7 shows the postulated predominant TAF degradation pathway proposed by Golla et al. [14]. First, the phosphoramidate moiety of TAF undergoes hydrolysis to form monophenyl-TFV (RRT of $\sim 0.6$ ) on the release of alanine isopropyl ester (RRT of $\sim 0.5$ ), then monophenyl-TFV further undergoes phosphorus phenyl ester hydrolysis to yield TFV (RRT of $\sim 0.36$ and 0.05 ).

(a)

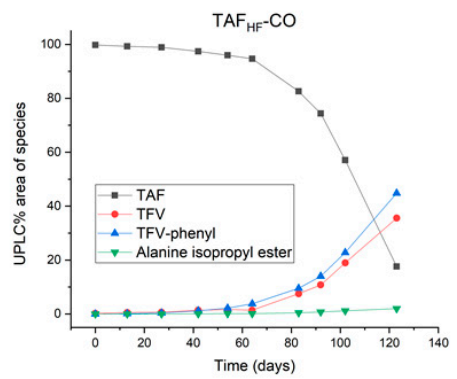

(c)

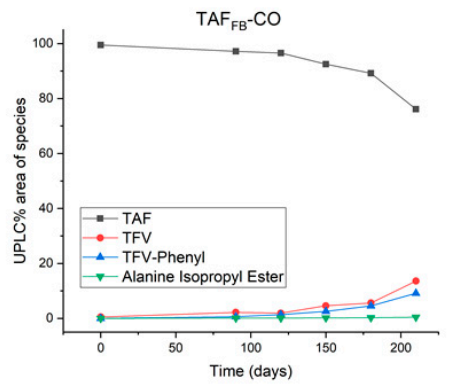

(b)

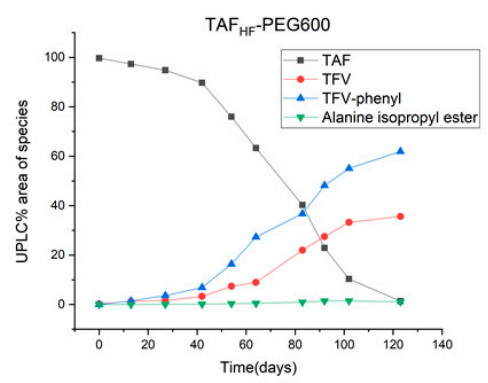

(d)

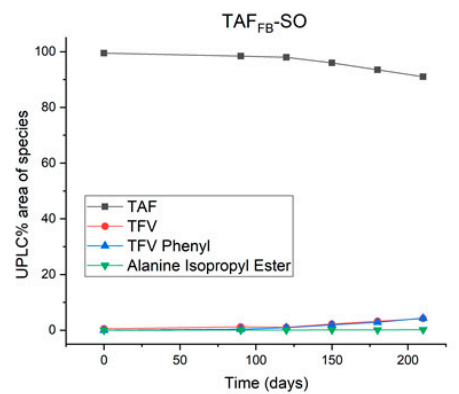

Figure 6. Chromatographic impurity profile of $\mathrm{TAF}_{\mathrm{HF}}-\mathrm{CO}(\mathbf{a}), \mathrm{TAF}_{\mathrm{HF}}-\mathrm{PEG} 600(\mathbf{b}), \mathrm{TAF}_{\mathrm{FB}}-\mathrm{CO}(\mathbf{c})$, and $\mathrm{TAF}_{\mathrm{FB}} \mathrm{SO}(\mathbf{d})$ formulations. 


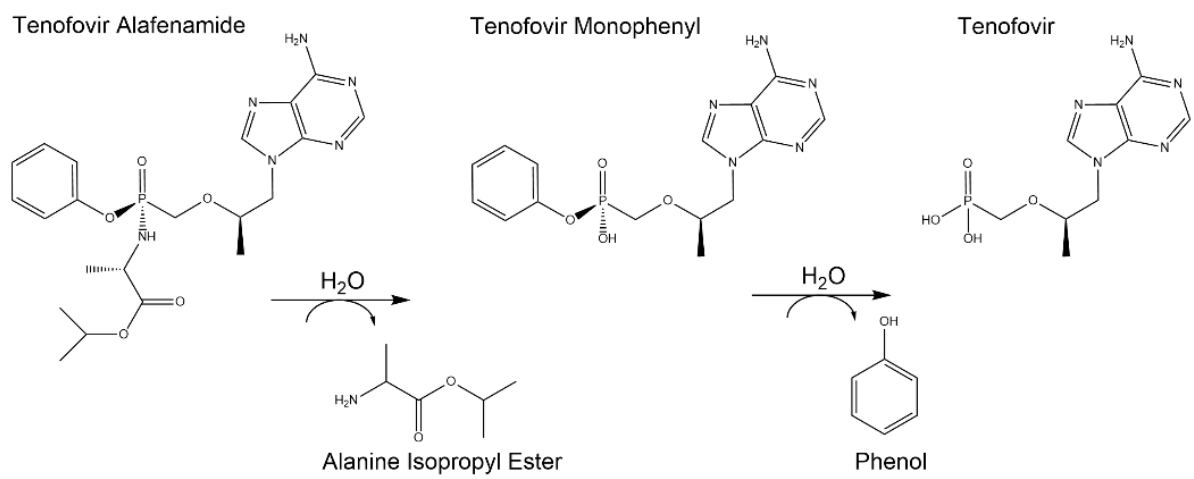

Figure 7. Postulated predominant TAF degradation pathway inside the implant reservoir.

\subsection{Six-Month Shelf-Stability of Implants with TAF Formulations}

To assess the stability of TAF formulations under different storage conditions we conducted a 6-month shelf stability study of the lead $\mathrm{TAF}_{\mathrm{HF}}$ and $\mathrm{TAF}_{\mathrm{FB}}$ formulations identified in the in-vitro evaluations. All the TAF implants comprised Sigma-PCL with a wall thickness of $70 \mu \mathrm{m}$ and formulations of a 2:1 weight ratio of $\mathrm{TAF}_{\mathrm{HF}}$ to castor oil or a 2:1 weight ratio of $\mathrm{TAF}_{\mathrm{FB}}$ to sesame oil. Implants were placed in open and closed foil pouches and then stored at $22{ }^{\circ} \mathrm{C} / 50 \% \mathrm{RH}$ and $40{ }^{\circ} \mathrm{C} / 75 \% \mathrm{RH}$ for six months. The long-term and accelerated storage conditions are selected based on FDA Guidance [30]. The purity of TAF within the implants was measured at 0, 90 and 180 days using the UPLC method. The chromatographic purity of each TAF formulation as a function of time is presented in Figure 8 and Table S5. As expected, formulations for both the $\mathrm{TAF}_{\mathrm{HF}}$ and the $\mathrm{TAF}_{\mathrm{FB}}$ formulations demonstrated higher stability under storage conditions as compared to aqueous in-vitro conditions. When the package remained intact, the stability of TAF remained $>97 \%$ for all formulations. Conversely, implants in the opened pouches, representing an unintentional breach in the packaging, resulted in substantially different stability profiles between $\mathrm{TAF}_{\mathrm{HF}}$ and $\mathrm{TAF}_{\mathrm{FB}}$. At 180 days in accelerated stability conditions $\left(40{ }^{\circ} \mathrm{C} / 75 \% \mathrm{RH}\right)$, the purity of $\mathrm{TAF}_{\mathrm{HF}}-\mathrm{CO}$ substantially decreased to $91.2 \%$, whereas the purity of $\mathrm{TAF}_{\mathrm{FB}}-\mathrm{SO}$ remained at $97.5 \%$. This result further shows that $\mathrm{TAF}_{\mathrm{FB}}$ outperforms $\mathrm{TAF}_{\mathrm{HF}}$ within the reservoir-style implant but also illustrates the importance of packaging design for future product translation efforts.

(a)

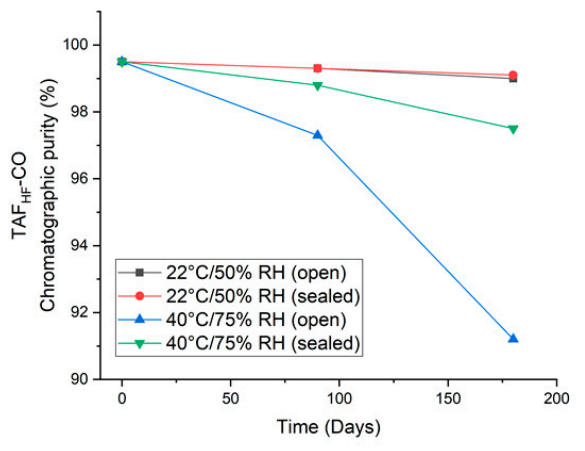

(b)

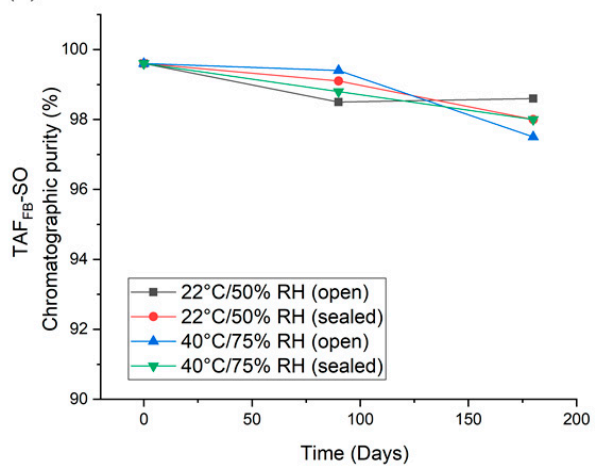

Figure 8. High-performance liquid chromatography (HPLC) chromatographic purity profile of 2:1 $\mathrm{TAF}_{\mathrm{HF}}-\mathrm{CO}(\mathbf{a})$ and 2:1 $\mathrm{TAF}_{\mathrm{FB}}-\mathrm{SO}(\mathbf{b})$ implants stored in open and closed foil pouches at $22{ }^{\circ} \mathrm{C} / 50 \% \mathrm{RH}$ and $40{ }^{\circ} \mathrm{C} / 75 \% \mathrm{RH}$ over 6 -months.

This shelf-stability study also identified the individual TAF degradants $>0.05 \%$ by RRT and LC-MS and showed the predominant degradants were monophenyl-TFV and TFV, as in the in-vitro studies. Figure 9 illustrates the levels of individual degradants at 180 days for various TAF formulations. Interestingly, TFV was detected at significantly higher levels than monophenyl-TFV for both $\mathrm{TAF}_{\mathrm{FB}}$ 
and $\mathrm{TAF}_{\mathrm{HF}}$ formulations under solid-state conditions of the shelf stability tests. For instance, $\mathrm{TAF}_{\mathrm{FB}}-\mathrm{SO}$ formulations contained $1.31 \pm 0.04 \%$ of TFV and $0.03 \pm 0.002 \%$ of monophenyl-TFV at 180 days, while $\mathrm{TAF}_{\mathrm{HF}}-\mathrm{CO}$ formulations showed $1.87 \pm 0.77 \%$ of TFV and $0.85 \pm 0.57 \%$ of monophenyl-TFV at 180 days.

(a)

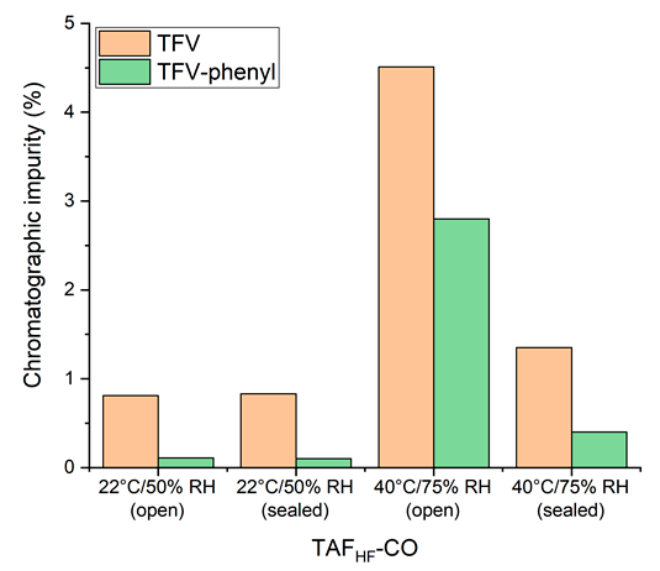

(b)

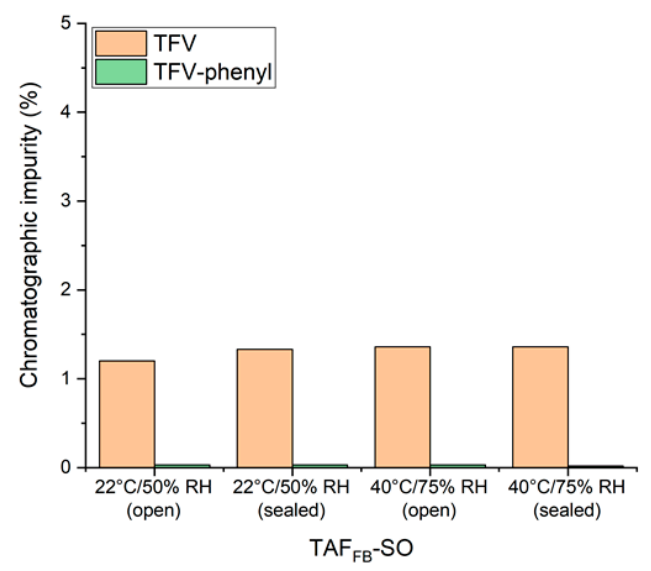

Figure 9. Chromatographic impurity of $\mathrm{TAF}_{\mathrm{HF}}-\mathrm{CO}(\mathbf{a})$ and $\mathrm{TAF}_{\mathrm{FB}}-\mathrm{SO}(\mathbf{b})$ formulations within the implant at 180 days under various storage conditions.

\subsection{Improving the Stability of $T A F_{F B}$ Formulations}

As discussed above, the degradation rate of TAF is $\mathrm{pH}$-dependent and is related to the rate of water ingress. To further enhance the stability of $\mathrm{TAF}_{\mathrm{FB}}$, Grattoni et al., included a trans-urocanic acid additive within an implant to preserve the optimal $\mathrm{pH}$ and maintain TAF purity $>90 \%$ in vitro for over 9 months [22]. We are currently exploring various $\mathrm{pH}$ modifiers and hydrophile lipophile balance (HLB) modifiers to further enhance the chemical stability of the $\mathrm{TAF}_{\mathrm{FB}}$ formulations [31,32]. Here, to improve the stability of TAF, we evaluated the ability to mitigate the amount of the water ingress by reducing the release rate of TAF. Previously we have demonstrated that the release rates of TAF from the implant are inversely proportional to the wall thickness of the PCL tubes [18]. In this study, we evaluated the release rate of $\mathrm{TAF}_{\mathrm{FB}}-\mathrm{CO}$ and $\mathrm{TAF}_{\mathrm{FB}}-\mathrm{SO}$ formulations within PCL tubes at 150, 200 and $300 \mu \mathrm{m}$ wall thickness. We used the PCL tubes comprising PC17, a medical-grade PCL with $M_{\mathrm{w}}$ of $93 \mathrm{kDa}$, to support future preclinical studies. Figure 10 shows the cumulative release profiles of the $\mathrm{TAF}_{\mathrm{FB}}-\mathrm{CO}$ and $\mathrm{TAF}_{\mathrm{FB}}-\mathrm{SO}$ implants at different wall thicknesses. Similarly, implants containing $\mathrm{TAF}_{\mathrm{FB}}-\mathrm{CO}$ formulations exhibited higher release rates than $\mathrm{TAF}_{\mathrm{FB}}-\mathrm{SO}$ implants. We also observed the inverse relationship between the thickness of PCL walls and the release rates of TAF for these medical-grade implants. For instance, as the wall thickness increased from 150 to $300 \mu \mathrm{m}$ for implants comprised of $\mathrm{TAF}_{\mathrm{FB}}-\mathrm{CO}$ formulation, the release rates of TAF decreased from $0.31 \pm 0.06 \mathrm{mg} /$ day to $0.10 \pm 0.02 \mathrm{mg} /$ day. The chromatographic purities of $\mathrm{TAF}_{\mathrm{FB}}-\mathrm{SO}$ and $\mathrm{TAF}_{\mathrm{FB}}-\mathrm{CO}$ formulations were assessed using the HPLC method at 210 and 240 days. As presented in Table 4, the chromatographic purity of TAF formulations is inversely correlated with the release rates of TAF, demonstrating the ability to delay the degradation of TAF by lowering the release rates of the implants and thus reducing the water ingress rate. After 240-day of in-vitro exposure, we achieved a purity of $93.2 \%$ for $\mathrm{TAF}_{\mathrm{FB}}-\mathrm{SO}$ formulation within $300 \mu \mathrm{m}$ implants. Importantly, thicker-wall implants also offer high mechanical strength and good device integrity. Although the release rate of $300 \mu \mathrm{m} \mathrm{TAF}_{\mathrm{FB}}-\mathrm{SO}$ implants is relatively low, the therapeutic level of TAF could be potentially achieved using multiple implants that are subcutaneously inserted, similar to Probuphine ${ }^{\circledR}$ [33] and Norplant ${ }^{\circledR}$ [34]. Although the use of multiple, low-dose implants will not circumvent the unavoidable hydrolysis of TAF within these current implant formulations, the use of multiple implants to achieve the desired dosing could extend the therapeutic duration to longer periods of time with protection. It is worth noting the degradation profile of TAF formulations assessed 
under in-vitro conditions may not be reflective of the in-vivo conditions and efforts are currently underway to evaluate the degradation profiles of the these TAF formulations in preclinical studies using animal models (i.e., rabbit, dog, non-human primate) [23].

(a)

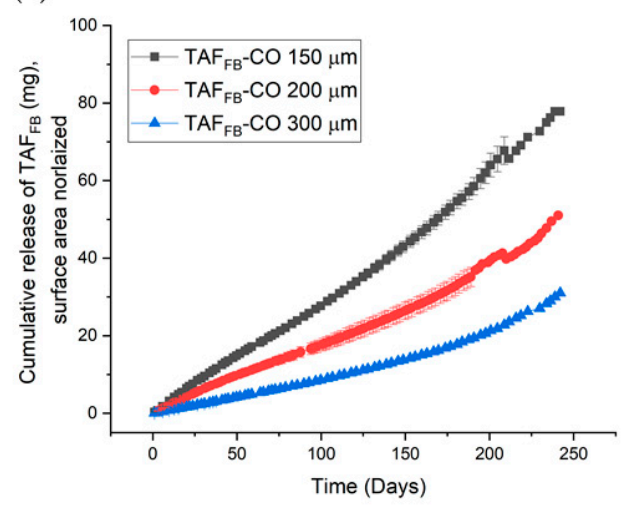

(b)

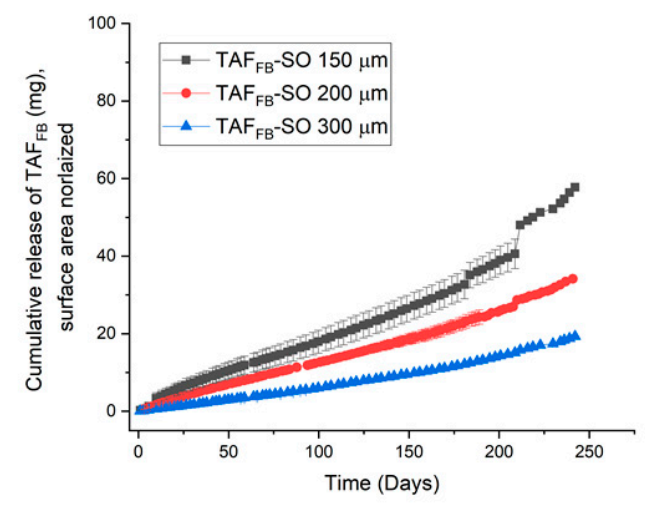

Figure 10. Cumulative release profiles of $\mathrm{TAF}_{\mathrm{FB}}-\mathrm{CO}(\mathbf{a})$ and $\mathrm{TAF}_{\mathrm{FB}}-\mathrm{SO}(\mathbf{b})$ formulations from implants of differing wall thicknesses. All samples were performed in triplicate.

Table 4. The chromatographic purities of $\mathrm{TAF}_{\mathrm{FB}}-\mathrm{SO}$ and $\mathrm{TAF}_{\mathrm{FB}}-\mathrm{CO}$ formulations within implants of differing wall thicknesses at 210 and 240 days.

\begin{tabular}{cccc}
\hline Implants & Release Rate (mg/day) & Purity at 210 Days (\%) & Purity at 240 Days (\%) \\
\hline $\mathrm{TAF}_{\mathrm{FB}}-\mathrm{SO} 150 \mu \mathrm{m}$ & $0.18 \pm 0.03$ & 94.3 & 88.8 \\
$\mathrm{TAF}_{\mathrm{FB}}-\mathrm{SO} 200 \mu \mathrm{m}$ & $0.11 \pm 0.04$ & 91.8 & 86.7 \\
$\mathrm{TAF}_{\mathrm{FB}}-\mathrm{SO} 300 \mu \mathrm{m}$ & $0.07 \pm 0.02$ & 96.1 & 93.2 \\
$\mathrm{TAF}_{\mathrm{FB}}-\mathrm{CO} 150 \mu \mathrm{m}$ & $0.31 \pm 0.06$ & 80.0 & 63.5 \\
$\mathrm{TAF}_{\mathrm{FB}}-\mathrm{CO} 200 \mu \mathrm{m}$ & $0.17 \pm 0.07$ & 81.2 & 67.9 \\
$\mathrm{TAF}_{\mathrm{FB}}-\mathrm{CO} 300 \mu \mathrm{m}$ & $0.10 \pm 0.02$ & 90.3 & 79.0 \\
\hline
\end{tabular}

\section{Conclusions}

This manuscript highlights the importance of the ionization form of a drug when developing implantable drug delivery systems. Although the ionized hemifumarate salt form of TAF is currently used in clinically available oral formulations, we show that the non-ionized free base form of TAF is better suited for our reservoir-style implant due to higher chemical stability over time. The development of implants as LA drug delivery systems require API formulations that maintain a high degree of purity when exposed to physiological conditions over extended periods, in many cases for months to years. These studies show that the $\mathrm{TAF}_{\mathrm{FB}}$ outperforms the $\mathrm{TAF}_{\mathrm{HF}}$ by maintaining higher purity for a longer time in a reservoir-style implant. The reasons for the higher purity of TAF $F_{\mathrm{FB}}$ is likely a result of multiple effects: slowed ingress rate of water due to lower release rates of $\mathrm{TAF}_{\mathrm{FB}}$, the absence of the fumarate salt and achievement of an optimum $\mathrm{pH}$ window. To further delay the hydrolysis of TAF within our implants, we used thicker PCL walls to reduce the rates of drug release and water ingress. Using this approach, a purity of $93.2 \%$ of TAF was achieved with $300 \mu \mathrm{m}$ implants comprising $\mathrm{TAF}_{\mathrm{FB}}-\mathrm{SO}$ formulation (release rate of $0.07 \mathrm{mg} /$ day) after 240-days of in-vitro exposure. In general, the delivery of hydrolysable drugs from an implant is feasible but requires careful consideration of attributes that could affect drug breakdown, including the implant form factor, mechanism of drug release, drug ionization form and environmental exposures (e.g., pH, temperature, water content). For the reservoir-style TAF implant presented in this paper, many of these parameters can be controlled to improve the stability of TAF and ultimately improve the performance of the implant for achieving long-acting HIV PrEP. 
Supplementary Materials: The following are available online at http://www.mdpi.com/1999-4923/12/11/1057/s1. Figure S1: Daily release profiles of implants filled with TAF hemifumarate salt (TAFHF) (a) and TAF freebase (TAFFB) (b). Table S1: Chromatographic purity of TAFHF formulated with castor oil or PEG600 inside implants exposed to simulated physiological conditions over 120 days. Table S2: Chromatographic purity of TAFFB formulated with sesame oil or castor oil inside implants exposed to simulated physiological conditions over 210 days. Table S3: Water ingress within the implant reservoir of TAFHF formulated with castor oil or PEG600 measured via the loss-on-drying method. Table S4: Water ingress within the implant reservoir of TAFFB formulated with castor oil or sesame oil measured via loss-on-drying method. Table S5: Chromatographic purity profile of TAFHF castor oil and TAFFB sesame oil implants stored in open and closed foil pouches stored at $22{ }^{\circ} \mathrm{C} / 50 \% \mathrm{RH}$ and $40{ }^{\circ} \mathrm{C} / 75 \%$ RH over 6-months.

Author Contributions: Conceptualization and Design, L.L., L.M.J., S.A.K, A.v.d.S.; Methodology, L.L., L.M.J., S.A.K.; Formal Analysis: L.L., L.M.J., S.A.K.; Writing: L.L., L.M.J., S.A.K, Z.R.D.; Review \& Editing, L.L., L.M.J, S.A.K., Z.R.D., A.v.d.S., Project Administration, Z.R.D.; Funding Acquisition, A.v.d.S. All authors have read and agreed to the published version of the manuscript.

Funding: This research was funded by the United States Agency for International Development through the U.S. President's Emergency Plan for AIDS Relief (AID-OAA-A-14-00012).

Acknowledgments: This research was made possible by the generous support of the American people by funding provided by the U.S. President's Emergency Plan for AIDS Relief through the United States Agency for International Development (USAID). We thank Gilead Sciences, Inc. for graciously providing TAF. We thank RTI team members: Natalie Girouard, Teresa Jester, Ellen Luecke, Pafio Johnson, Christine Areson, Guadalupe Arce Jimenez and Marza Hill for data collection and Dayle Johnson for Figure 1 drawing.

Conflicts of Interest: The authors declare no conflict of interest.

\section{References}

1. UNAIDS Data 2020. Joint United Nations Programme on HIV/AIDS (UNAIDS). Available online: https: //www.unaids.org/en/resources/documents/2020/unaids-data (accessed on 6 July 2020).

2. UNAIDS. Global AIDS Update-Executive Summary: Seizing the Moment. Available online: https://www. unaids.org/sites/default/files/media_asset/2020_global-aids-report_executive-summary_en.pdf (accessed on 10 October 2020).

3. Dapivirine Vaginal Ring 25 mg-Summary of Opinion; EMA/CHMP/330850/2020; Eropean Medical Agency: Amsterdam, The Netherlands, 2020.

4. Landovitz, R.J.; Donnell, D.; Clement, M.; Hanscom, B.; Cottle, L.; Coelho, L.; Cabello, R.; Chariyalestak, S.; Dunne, E.; Frank, I.; et al. Pre-exposure prophylaxis (PrEP) containing long-acting injectable cabotegravir (CAB-LA) is safe and highly effective for cisgender men and transgender women who have sex with men (MSM, TGW). Late breaker oral abstract OAXLB0101. In Proceedings of the Oral Abstracts from the 23rd International AIDS Conference, San Francisco, CA, USA, 6-10 July 2020.

5. Ollila, E.; Sihvo, S.; Merilainen, J.; Hcmminki, E. Experience of Finnish Women with Norplant Insertions and Removals. BJOG Int. J. Obstet. Gynaecol. 1997, 104, 488-494. [CrossRef] [PubMed]

6. Flexner, C. Antiretroviral Implants for Treatment and Prevention of HIV Infection. Curr. Opin. HIV AIDS 2018, 13, 374-380. [CrossRef] [PubMed]

7. Tsai, C.-C.; Follis, K.E.; Sabo, A.; Beck, T.W.; Grant, R.F.; Bischofberger, N.; Benveniste, R.E.; Black, R. Prevention of SIV Infection in Macaques by (R)-9-(2-Phosphonylmethoxypropyl) adenine. Science 1995, 270, 1197-1199. [CrossRef] [PubMed]

8. De Clercq, E. The role of tenofovir in the prevention of HIV infections. AIDS 2006, 20, 1990-1991. [CrossRef]

9. Ray, A.S.; Fordyce, M.W.; Hitchcock, M.J. Tenofovir Alafenamide: A Novel Prodrug of Tenofovir for the Treatment of Human Immunodeficiency Virus. Antivir. Res. 2016, 125, 63-70. [CrossRef]

10. Lee, W.A.; He, G.-X.; Eisenberg, E.; Cihlar, T.; Swaminathan, S.; Mulato, A.; Cundy, K.C. Selective Intracellular Activation of a Novel Prodrug of the Human Immunodeficiency Virus Reverse Transcriptase Inhibitor Tenofovir Leads to Preferential Distribution and Accumulation in Lymphatic Tissue. Antimicrob. Agents Chemother. 2005, 49, 1898-1906. [CrossRef] [PubMed]

11. Markowitz, M.; Zolopa, A.; Squires, K.; Ruane, P.; Coakley, D.; Kearney, B.; Zhong, L.; Wulfsohn, M.; Miller, M.D.; Lee, W.A. Phase I/II Study of the Pharmacokinetics, Safety and Antiretroviral Activity of Tenofovir Alafenamide, A New Prodrug of The Hiv Reverse Transcriptase Inhibitor Tenofovir, in HIV-infected adults. J. Antimicrob. Chemother. 2014, 69, 1362-1369. [CrossRef] [PubMed] 
12. Emtricitabine/Tenofovir Alafenamide-Nonclinical Overview. Available online: https://www.pmda.go.jp/ drugs/2016/P20161209001/530614000_22800AMX00716_F100.pdf (accessed on 7 July 2020).

13. Golla, V.M.; Kurmi, M.; Shaik, K.; Singh, S. Stability Behaviour of Antiretroviral Drugs and Their Combinations. 4: Characterization of Degradation Products of Tenofovir Alafenamide Fumarate and Comparison of Its Degradation and Stability Behaviour with Tenofovir Disoproxil Fumarate. J. Pharm. Biomed. Anal. 2016, 131, 146-155. [CrossRef] [PubMed]

14. Gunawardana, M.; Remedios-Chan, M.; Miller, C.S.; Fanter, R.; Yang, F.; Marzinke, M.A.; Hendrix, C.W.; Beliveau, M.; Moss, J.A.; Smith, T.J.; et al. Pharmacokinetics of Long-Acting Tenofovir Alafenamide (GS-7340) Subdermal Implant for HIV Prophylaxis. Antimicrob. Agents Chemother. 2015, 59, 3913-3919. [CrossRef]

15. Su,J.T.; Simpson, S.M.; Sung, S.; Tfaily, E.B.; Veazey, R.; Marzinke, M.; Qiu, J.; Watrous, D.; Widanapathirana, L.; Pearson, E.; et al. A Subcutaneous Implant of Tenofovir Alafenamide Fumarate Causes Local Inflammation and Tissue Necrosis in Rabbits and Macaques. Antimicrob. Agents Chemother. 2019, 64. [CrossRef]

16. Pons-Faudoa, F.P.; Sizovs, A.; Shelton, K.A.; Momin, Z.; Bushman, L.R.; Xu, J.; Chua, C.Y.X.; Nichols, J.E.; Hawkins, T.; Rooney, J.F.; et al. Preventive Efficacy of A Tenofovir Alafenamide Fumarate Nanofluidic Implant in Shiv-Challenged Nonhuman Primates. BioRxiv 2020. [CrossRef]

17. Johnson, L.M.; Krovi, S.A.; Li, L.; Girouard, N.; Demkovich, Z.R.; Myers, D.; Creelman, B.; Van Der Straten, A. Characterization of a Reservoir-Style Implant for Sustained Release of Tenofovir Alafenamide (TAF) for HIV Pre-Exposure Prophylaxis (PrEP). Pharmaceutics 2019, 11, 315. [CrossRef]

18. CAPRISA 018: A phase I/II trial to assess the safety, acceptability and pharmacokinetics of a sustained-release tenofovir alafenamide sub-dermal implant for HIV prevention in women. V2.0. 12 August 2019. Available online: https://www.caprisa.org/DBFile/Files/0a88623f-c1ce-455d-9ecd-648dfd03b620/CAPRISA\%20018_ Study\%20protocol\%20V2.0_12\%20Aug\%202019.pdf (accessed on 10 October 2020).

19. Simpson, S.M.; Widanapathirana, L.; Su, J.T.; Sung, S.; Watrous, D.; Qiu, J.; Pearson, E.; Evanoff, A.; Karunakaran, D.; Chacon, J.E.; et al. Design of a Drug-Eluting Subcutaneous Implant of the Antiretroviral Tenofovir Alafenamide Fumarate. Pharm. Res. 2020, 37, 83. [CrossRef]

20. Chua, C.Y.X.; Jain, P.; Ballerini, A.; Bruno, G.; Hood, R.L.; Gupte, M.; Gao, S.; Di Trani, N.; Susnjar, A.; Shelton, K.; et al. Transcutaneously Refillable Nanofluidic Implant Achieves Sustained Level of Tenofovir Diphosphate for HIV Pre-Exposure Prophylaxis. J. Control. Release 2018, 286, 315-325. [CrossRef] [PubMed]

21. Sizovs, A.; Pons-Faudoa, F.P.; Malgir, G.; Shelton, K.A.; Bushman, L.R.; Chua, C.Y.X.; Anderson, P.L.; Nehete, P.N.; Sastry, K.J.; Grattoni, A. Trans-Urocanic Acid Enhances Tenofovir Alafenamide Stability for Long-Acting HIV Applications. Int. J. Pharm. 2020, 587, 119623. [CrossRef] [PubMed]

22. Gatto, G.J.; Krovi, S.A.; Johnson, L.M.; Demkovich, Z.R.; Marzinke, M.A.; Luecke, E.; van der Straten, A. Sustained 6-month Release Of Tenofovir Alafenamide (TAF) from A Biodegradable Implant For Long-acting (LA)-HIV Pre-Exposure Prophylaxis (PrEP). In Proceedings of the Controlled Release Society, Las Vegas, NV, USA, 27 June-1 July 2020.

23. Gupta, B.; Geeta; Ray, A.R. Preparation of poly( $\varepsilon$-caprolactone)/poly( $\varepsilon$-caprolactone-co-lactide) (PCL/PLCL) Blend Filament by Melt Spinning. J. Appl. Polym. Sci. 2011, 123, 1944-1950. [CrossRef]

24. Obregon, N.; Agubra, V.; Pokhrel, M.; Campos, H.; Flores, D.; De La Garza, D.; Mao, Y.; Macossay, J.; Alcoutlabi, M. Effect of Polymer Concentration, Rotational Speed, and Solvent Mixture on Fiber Formation Using Forcespinning ${ }^{\circledR}$. Fibers 2016, 4, 20. [CrossRef]

25. Schlesinger, E.; Ciaccio, N.; Desai, T.A. Polycaprolactone Thin-Film Drug Delivery Systems: Empirical and Predictive Models for Device Design. Mater. Sci. Eng. C 2015, 57, 232-239. [CrossRef]

26. Siepmann, J.; Siege, R.A.; Rathbone, M.J. Fundamentals and Applications of Controlled Release Drug Delivery; Springer: Boston, MA, USA, 2012. [CrossRef]

27. Berger, J.E.; Wittner, E. Adsorption of Phosphoramidates on Iron. J. Phys. Chem. 1966, 70, 1025-1030. [CrossRef]

28. Garrison, A.W.; Boozer, C.E. The Acid-Catalyzed Hydrolysis of A Series of Phosphoramidates. J. Am. Chem. Soc. 1968, 90, 3486-3494. [CrossRef]

29. FDA Guidance for Industry. Q1A(R2) Stability Testing of New Drug Substances and Products. Available online: https://www.fda.gov/media/71707/download (accessed on 31 July 2020).

30. Shah, T. Stabilization of a Tenofovir Alafenamide Fumarate Formulation for Use in a Subcutaneous Implant. Master's Thesis, University of Pittsburgh, Pittsburgh, PA, USA, 2019. 
31. Bagia, C.; Shah, T.; Johnson, L.M.; Krovi, S.A.; Demkovich, Z.R.; van der Straten, A. Development of Novel Accelerated Stability Testing Models for Tenofovir Alafenamide (TAF) in Long-Acting Implants for HIV Prevention. In Proceedings of the Controlled Release Society, Las Vegas, NV, USA, 27 June-1 July 2020.

32. Product Pipeline. PROBUPHINE®(buprenorphine) Implant. Available online: https://www.titanpharm. com/pipeline/probuphine (accessed on 15 September 2020).

33. Pasquale, S.A.; Brandeis, V.; Cruz, R.; Kelly, S.; Sweeney, M. Norplant ${ }^{\circledR}$ Contraceptive Implants: Rods Versus Capsules. Contraception 1987, 36, 305-316. [CrossRef]

34. Schlesinger, E.; Johengen, D.; Luecke, E.; Rothrock, G.; McGowan, I.; van der Straten, A.; Desai, T. A Tunable, Biodegradable, Thin-Film Polymer Device as a Long-Acting Implant Delivering Tenofovir Alafenamide Fumarate for HIV Pre-exposure Prophylaxis. Pharm. Res. 2016, 33, 1649-1656. [CrossRef]

Publisher's Note: MDPI stays neutral with regard to jurisdictional claims in published maps and institutional affiliations.

(C) 2020 by the authors. Licensee MDPI, Basel, Switzerland. This article is an open access article distributed under the terms and conditions of the Creative Commons Attribution (CC BY) license (http://creativecommons.org/licenses/by/4.0/). 